\title{
Influence of Temperature and Ion Concentration on Sedimentation Characteristics of Tricalcium phosphate (TCP) and Tristrontium phosphate (TSP) Precipitates
}

\author{
OBUNWO, CC*; IBOROMA, SD; COOKEY, GA
}

\author{
Department of Chemistry, Rivers State University, Port Harcourt, Nigeria \\ *corresponding author: obunwo.charles@ust.edu.ng
}

\begin{abstract}
Physical and chemical variables of insoluble salts generally affect sedimentation characteristics of precipitates. In this research study, the effects of temperature and ion concentration on the sedimentation of tricalcium phosphate (TCP) and tristrontium phosphate (TSP) were studied. The focus was to determine the sedimentation kinetics such as rate, order and rate constant of TCP and TSP at varying temperatures using the modified initial rate (Isolation) method. It was observed that whereas effect of temperature was not significant, low concentrations $(<0.04 \mathrm{M})$ of the metal and phosphate ions markedly influenced the initial sedimentation rates of TCP and TSP precipitates.TCP sedimentation order ranged between 0.63 and 1.23 at constant phosphate ions concentration and between 1.52 and 2.10 at constant calcium ions concentration. TSP sedimentation order also ranged between 0.58 and 1.31 at constant phosphate ions concentration and between 1.55 and 1.81 at constant strontium ions concentration. Furthermore, ranges of sedimentation rate constants were obtained. At constant phosphate ions concentration, $1.80 \times 10^{-4}-1.57 \times 10^{-3}$ and $1.51 \times 10^{-4}-2.45 \times 10^{-3}$ were obtained for TCP and TSP, respectively. At constant metal ions concentration $1.71 \times 10^{-5}-9.54 \times 10^{-5}$ and $5.70 \times 10^{-5}-1.12 \times 10^{-4}$ were respectively obtained for TCP and TSP. Data may be employed as additional design information for modeling physiochemical phosphate removal in water treatment technology.
\end{abstract}

DOI: https://dx.doi.org/10.4314/jasem.v21i7.28

Copyright @ 2017 Obunwo et al. This is an open access article distributed under the Creative Commons Attribution NonCommercial License (CC-BY-NC), which permits unrestricted use, distribution, and reproduction in any medium, provided the original work is properly cited.

\section{Received 15 September 2017, received in revised form 15 October 2017, accepted 16 December 2017}

Keywords: sedimentation rate, sedimentation characteristics, tricalcium phosphate, tristrontium phosphate.

Sedimentation describes the motion of particles in suspension or molecules in solution in response to an external force such as gravity (Fatimi et al., 2010). It is a physical process commonly used to remove impurities that have been rendered settleable by precipitation or flocculation in wastewater treatment technology. Rate data of sedimentation is useful in the design of sedimentation tanks and in modeling two-phase flow operations (Obunwo and Iboroma, 2015).

Mathematical models such as those by Stokes and Vesilind respectively describe sedimentation of particles in dilute and concentrated suspension media (Nutan and Reddy, 2010; Zhang et al., 2015). According to Kazadi-Mbamba et al., (2015) existing models have limited description for physico-chemical processes such as precipitation, possibly due to design limitations. However, Obunwo et al., (2017) postulated that they describe sedimentation data that originate purely from physical processes.

Suspensions prepared by precipitation methods (Patel, 2010) settle out in response to gravitational force and at different rates depending on concentration of the solutions before mixing and the degree of particle supersaturation in mixture after mixing. Precipitation conditions (Kirboga and Oner, 2013) that influence particle size and structure temperature, concentration of reactants, stirring, $\mathrm{pH}$ of medium - also affect the sedimentation behaviour of resulting precipitates.

In continuation of our studies on sedimentation, we have investigated the effects of temperature and ion concentration on sedimentation properties of tricalcium and tristrontium phosphates in mother solution, by the modified Initial Rate (or Isolation) Method. The objective of this paper is to present the influence of temperature and ion concentration on sedimentation characteristics of tricalcium phosphate (TCP) and tristrontium phosphate (TSP) Precipitates.

\section{MATERIALS AND METHODS}

Materials such as analytical grade (BDH chemicals) trisodium phosphate, calcium chloride and strontium chloride hexahydrate were procured. Other materials employed included digital stopwatch, thermometer, Nuohai thermostated water-bath (Model Number XMTD-204) and a digital camera. A bench-scale settling apparatus (settleometer) was set up using $100 \mathrm{ml}$ measuring cylinder, a transparent measuring tape and stirring rod.

Treatment: Standard solutions $(0.02 \mathrm{M}-10 \mathrm{M})$ of calcium chloride, strontium chloride and trisodium phosphate were prepared using de-ionised water. The experimental study approach employed for this study was the 'Modified Initial Rate or Isolation Method' (Atkins and Paula, 2006; Obunwo et al., 2014). 
Known volumes $(40 \mathrm{mls})$ of varying concentration of either $\mathrm{Ca}^{2+}$ or $\mathrm{Sr}^{2+}(0.02 \mathrm{M}$ to $0.10 \mathrm{M})$ and constant concentration of $\mathrm{PO}_{4}{ }^{3-}(0.06 \mathrm{M})$ were mixed directly to form either tricalcium phosphate (TCP), $\mathrm{Ca}_{3}\left(\mathrm{PO}_{4}\right)_{2}$, or tristrontium phosphate (TSP), $\mathrm{Sr}_{3}\left(\mathrm{PO}_{4}\right)_{2}$, precipitates. The precipitate suspension formed after mixing was stirred immediately for 30 seconds and then allowed to stand. The displacement of the suspension front (h) was monitored and recorded every 30 seconds, for 150 seconds. The procedure was reversed by varying the concentration of the $\mathrm{PO}_{4}{ }^{3-}$ while keeping either $\mathrm{Ca}^{2+}$ or $\mathrm{Sr}^{2+}$ concentration constant. The experiments were performed in a thermostated water-bath set initially at $30^{\circ} \mathrm{C}$ and were repeated at $35,40,45,50$, and $55^{\circ} \mathrm{C}$. A 3.1 watts LED rechargeable desk lamp was provided to enhance illumination. A digital camera was also benchmounted and set to capture images of the suspension front.

Sedimentation rate (Rs) may be expressed, at low particle concentration, in discrete settling mode as Equation 1 according to Stokes (Nutan and Reddy, 2010).

$$
R s=\frac{d h}{d t}=\frac{d^{2}\left(\rho_{1}-\rho_{2}\right) g}{18 \mu}
$$

where $R s=$ sedimentation rate, $d=$ diameter of the particle, $\rho_{1}=$ density of disperse phase, $\rho_{2}=$ density of dispersion medium, $\mathrm{g}=$ acceleration due to gravity and $\mu=$ viscosity of the dispersion medium.

When particle concentration is high, Stokes' equation may not show the real sedimentation rate. Vasilind and Dick and Young introduced equations 2 and 3 to accommodate suspensions with high particle content (Zhang et al., 2015).

$$
\begin{aligned}
& R s=\frac{d h}{d t}=V_{0} \exp ^{-n X} \\
& R s=\frac{d h}{d t}=V_{0} X^{-n}
\end{aligned}
$$

where $R s=$ sedimentation rate, $V_{0}=$ maximum sedimentation rate, $X=$ solid concentration and $\mathrm{n}=$ sedimentation index.

The sedimentation behaviour of insoluble material (precipitate) from solution medium depends upon the concentrations of reacting species (Essien and Ekpe, 1998) .Changes in height $(d h)$ against time $(d t)$ were plotted as sedimentation rate curves for the determination of initial sedimentation rate (Rs). Plots of $\log$ (Rs) against log (ion species) determined other sedimentation characteristics.

\section{RESULTS AND DISCUSSION}

Variation of TCP and TSP Initial Sedimentation Rates with Temperature and Concentration:

Figures 1 to 4 express the results of initial sedimentation rates of TCP and TSP as functions of temperature at different metal and phosphate concentrations. They show that initial sedimentation rate is independent of temperature variation but is markedly influenced by low concentrations $(<$
$0.04 \mathrm{M}$ ) of metal and phosphate ions. Rise in temperature from 30 to $55^{\circ} \mathrm{C}$, gave poor negatively correlated (non-linear) initial sedimentation rate profiles of TCP and TSP for 0.02 and $0.04 \mathrm{M}$ metal and phosphate ions concentrations. Temperature effects leveled out completely from $0.06 \mathrm{M}$ and beyond, possibly due to high particle (precipitate) content. However, the results show that at the various temperatures, initial sedimentation rates of TCP and TSP were high at low concentration of both the metal and phosphate ions. For example, at $35^{\circ} \mathrm{C}$ initial sedimentation rate of TCP (or TSP) decreased from $\left(0.062 \mathrm{cms}^{-1}\right.$ to $\left.0.010 \mathrm{cms}^{-1}\right)$ or $\left(0.036 \mathrm{cms}^{-1}\right.$ to $\left.0.018 \mathrm{cms}^{-1}\right)$ when calcium and strontium ions concentrations respectively increased from $0.02 \mathrm{M}$ to $0.04 \mathrm{M}$. From $0.04 \mathrm{M}$ to $0.06 \mathrm{M}$ calcium or strontium ions concentrations, the initial sedimentation rates only dropped from $\left(0.010 \mathrm{cms}^{-1}\right.$ to $\left.0.007 \mathrm{cms}^{-1}\right)$ or $\left(0.018 \mathrm{cms}^{-1}\right.$ to $\left.0.009 \mathrm{cms}^{-1}\right)$. Similarly, when phosphate ions concentration increased from $0.02 \mathrm{M}$ to $0.04 \mathrm{M}, \mathrm{TCP}$ (or TSP) precipitate initial sedimentation rate passed down from $\left(0.068 \mathrm{cms}^{-1}\right.$ to $\left.0.013 \mathrm{cms}^{-1}\right)$ or $\left(0.072 \mathrm{cms}^{-1}\right.$ to $\left.0.041 \mathrm{cms}^{-1}\right)$. From $0.04 \mathrm{M}$ to $0.06 \mathrm{M}$ phosphate ions concentration, the initial sedimentation rates of TCP (or TSP) precipitate again only dropped from $\left(0.013 \mathrm{cms}^{-1}\right.$ to $\left.0.007 \mathrm{cms}^{-1}\right)$ or $\left(0.041 \mathrm{cms}^{-1}\right.$ to $\left.0.015 \mathrm{cms}^{-1}\right)$. By direct mixing, various degrees of particle concentration were created in the reaction vessel. High particle concentration promotes particle-particle interactions and results in hindered sedimentation (Punnamaraju, 2012; Mastropietro et al., 2013); thus lower sedimentation rate. High temperature also enhances particle-medium interactions (Gary, 2004), which increased the tendency for the particles to remain stabilized at the initial precipitation stages. Solutiondriven interactions of the precipitates with $\mathrm{H}^{+}$and $\mathrm{OH}^{-}$of the aqueous medium (Bouchoud, et al., 2010; Recillas, et al., 2012) would also be high at high temperature. The visual observation employed did not give much clue on interactions except that at temperatures above $40^{\circ} \mathrm{C}$, it was observed that the haziness of the suspension mixtures (particularly the $0.02 \mathrm{M}$ concentration), as seen through the transparent settleometer, slightly decreased. Although, rising temperature also causes decrease in medium viscosity (Nutan and Reddy, 2010), it is likely that the degree of interactions (particle-particle and particle-medium) out-weighed the decrease of viscosity and sedimentation rate of precipitate, Rs, may be expressed as (Victor et al., 2007):

$$
R_{s}=K_{s}\left[M^{+2}\right]^{-a}\left[\mathrm{PO}_{4}^{3-}\right]^{-b}
$$

The empirical sedimentation order (a) and sedimentation rate constant $\left(\mathrm{Ks}_{\mathrm{M}}\right)$ with respect to the metal ions concentration were evaluated by keeping $\left[\mathrm{PO}_{4}{ }^{3-}\right]$ constant (or isolated) as:

$$
R_{S M}=K_{S M}\left[M^{2+}\right]^{-a}
$$

Similarly, the empirical sedimentation order (b) and sedimentation rate constant $\left(\mathrm{Ks}_{\mathrm{P}}\right)$ with respect to the 
phosphate ions concentration were evaluated by keeping $\left[\mathrm{M}^{2+}\right]$ constant (or isolated) as:

$$
R_{S P}=K_{S P}\left[\mathrm{PO}_{4}^{3-}\right]^{-b}
$$

$\mathrm{Rs}_{\mathrm{M}}$ and $\mathrm{Rs}_{\mathrm{P}}$ are the initial sedimentation rates of precipitates with respect to metal ions $\left(\mathrm{Ca}^{2+}\right.$ or $\left.\mathrm{Sr}^{2+}\right)$ and phosphate ions concentrations respectively.

Sedimentation Rate Parameters of TCP and TSP Precipitates: From the data obtained, the other sedimentation characteristics of TCP and TSP (Tables 1 and 2) indicate that, at constant phosphate ions concentration, sedimentation order with respect to metal ions (a) ranged between 0.63 and 1.23 for TCP and 0.58 and 1.31 for TSP. Also, at constant metal ions concentration, sedimentation order with respect to phosphate ions concentration (b) ranged between 1.52 and 2.10 for TCP and 1.55 and 1.81 for TSP.

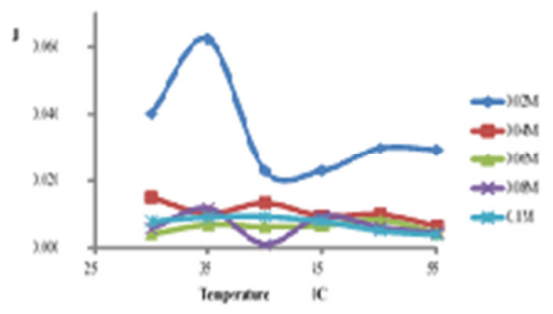

Fig 1: Initial sedimentation rate of TCP precipitate as function of temperature for various $\left[\mathrm{Ca}^{2+}\right]$.

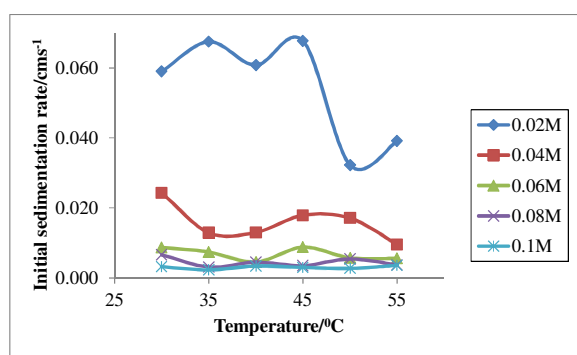

Fig 2: Initial sedimentation rate of TCP precipitate as function of temperaturefor various $\left[\mathrm{PO}_{4}{ }^{3-}\right]$.

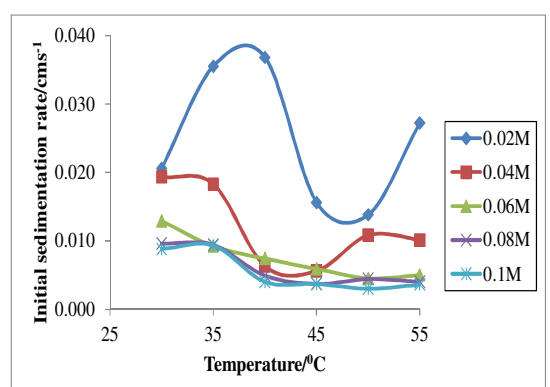

Fig 3: Initial sedimentation rate of TSP precipitate as function of temperature for various $\left[\mathrm{Sr}^{2+}\right]$.

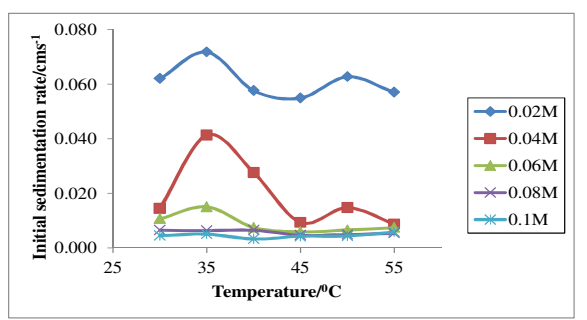

Fig 4:Initial sedimentation rate of TSP precipitate as function of temperature for various $\left[\mathrm{PO}_{4}{ }^{3-}\right]$.

The empirical sedimentation order and sedimentation rate constant (Tables 1 and 2) gave no linear correlation with temperature. This suggest that the order and rate constant of sedimentation cannot be predicted by temperature variations; their values may depend on the nature of the precipitant ions forming the precipitate and the size (colloidal) of the precipitate particle formed. In an earlier study on magnesium and calcium carbonate sedimentation, Obunwo et al., (2014) suggested that the sedimentation rate constant was an intrinsic property which depended among others factors, on the nature of precipitate formed.$$
\text { . }
$$

Table 1: Kinetic Parameters on the Sedimentation of $\mathrm{Ca}_{3}\left(\mathrm{PO}_{4}\right)_{2}$ precipitate at different Temperatures

\begin{tabular}{llccc}
\hline Temperature, ${ }^{\circ} \mathrm{C}$ & $\begin{array}{c}\text { Sedimentation Order (a) } \\
\text { at constant }\left[\mathrm{PO}_{4}{ }^{3-}\right]\end{array}$ & $\begin{array}{c}\text { Sedimentation Rate } \\
\text { Constant, } \mathrm{ks}_{\mathrm{Ca}} \text {, at constant } \\
{\left[\mathrm{PO}_{4}{ }^{3-}\right] \mathrm{cms}^{-1} \mathrm{M}}\end{array}$ & $\begin{array}{c}\text { Sedimentation Order (b) } \\
\text { at constant }\left[\mathrm{Ca}^{2+}\right]\end{array}$ & $\begin{array}{c}\text { Sedimentation Rate } \\
\mathrm{Constant} \mathrm{ks} \text {, at constant } \\
{\left[\mathrm{Ca}^{2+}\right] \mathrm{cms}^{-1} \mathrm{M}}\end{array}$ \\
\hline 30 & 1.21 & $2.89 \times 10^{-4}$ & 1.78 & $6.32 \times 10^{-5}$ \\
35 & 1.11 & $5.11 \times 10^{-4}$ & 2.10 & $1.71 \times 10^{-5}$ \\
40 & 1.21 & $2.01 \times 10^{-4}$ & 1.83 & $3.98 \times 10^{-5}$ \\
45 & 0.63 & $1.57 \times 10^{-3}$ & 2.01 & $2.73 \times 10^{-5}$ \\
50 & 1.07 & $4.04 \times 10^{-4}$ & 1.52 & $9.54 \times 10^{-5}$ \\
55 & 1.23 & $1.80 \times 10^{-4}$ & 1.53 & $8.51 \times 10^{-5}$ \\
\hline
\end{tabular}

Table 2: Kinetic Parameters on the Sedimentation of $\mathrm{Sr}_{3}\left(\mathrm{PO}_{4}\right)_{2}$ precipitate at different Temperatures

\begin{tabular}{|c|c|c|c|c|}
\hline Temperature, ${ }^{\circ} \mathrm{C}$ & $\begin{array}{l}\text { Sedimentation Order } \\
\text { (a) at constant }\left[\mathrm{PO}_{4}{ }^{3-}\right]\end{array}$ & $\begin{array}{c}\text { Sedimentation Rate } \\
\text { Constant } \mathrm{ks}_{\mathrm{Sr}} \text {, at constant } \\
{\left[\mathrm{PO}_{4}{ }^{3-}\right] \mathrm{cms}^{-1} \mathrm{M}}\end{array}$ & $\begin{array}{l}\text { Sedimentation Order (b) } \\
\text { at constant }\left[\mathrm{Sr}^{2+}\right]\end{array}$ & $\begin{array}{c}\text { Sedimentation Rate } \\
\text { Constant ks} \text {, at constant } \\
{\left[\mathrm{Sr}^{2+}\right] \mathrm{cms}^{-1} \mathrm{M}}\end{array}$ \\
\hline 30 & 0.58 & $2.45 \times 10^{-3}$ & 1.59 & $1.12 \times 10^{-4}$ \\
\hline 35 & 0.90 & $9.67 \times 10^{-4}$ & 1.77 & $9.16 \times 10^{-5}$ \\
\hline 40 & 1.28 & $1.82 \times 10^{-4}$ & 1.81 & $5.70 \times 10^{-5}$ \\
\hline 45 & 0.88 & $4.37 \times 10^{-4}$ & 1.60 & $7.89 \times 10^{-5}$ \\
\hline 50 & 0.98 & $3.43 \times 10^{-4}$ & 1.72 & $6.40 \times 10^{-5}$ \\
\hline 55 & 1.31 & $1.51 \times 10^{-4}$ & 1.55 & $9.75 \times 10^{-5}$ \\
\hline
\end{tabular}


Conclusion: We have studied the effects of temperature and ion concentration on the initial sedimentation rates of TCP and TSP precipitates by the method of initial rate. It was found that initial sedimentation rate is independent of temperature variation but is markedly influenced by low concentrations $(<0.04 \mathrm{M})$ of the metal and phosphate ions. The sedimentation orders and sedimentation rate constants of TCP and TSP showed no dependence on temperature. The nature and concentration of ions, size (colloidal) of the particle, high particle content, particle-particle and particle-medium interactions affect initial sedimentation rate of precipitates. Data may be useful as additional design information for modeling temperature and concentration variations for physiochemical phosphate removal in water treatment technology.

\section{REFERENCES}

Atkins, P; Paula, JD (2006). Atkins Physical Chemistry (8th ed.). Oxford University Press, New Delhi, India.

Bouchoud, L; Fonzo-Christie, C; Sadeghipour, F; Bonnabry, P (2010).Maximizing calcium and phosphate content in neonatal parenteral nutrition solutions using organic calcium and phosphate salts. J. Parenteral and Enteral Nutrition 34 (5): 542 - 545.

Essien, IO; Ekpe, SD (1998). Determination of sedimentation rates of cobalt(II) insoluble compounds and absorption coefficient of the sedimenting particles using gamma radiation. $J$. Chem. Soc. Pak. 20 (2): 120 - 124.

Gary, D (2004). Analytical Chemistry (6th ed.). John Wiley, Singapore.

Fatimi, A; Tassin, J; Axelos, MA; Weiss, P (2010). The stability mechanism of an injectable calcium phosphate ceramic suspension.J. Mat. Sci.21 (6):1799 - 1809.

Kazadi-Mbamba, C; Tait, S; Flores-Alsina, X; Batstone, DJ (2015). Dynamic modeling and identification of precipitation reactions in fullscale WWTP. 9th IWA Symposium onSystems Analysis and Integrated Assessment. Goldcoast, Australia.

Kirboga, S; Oner, M (2013). Effects of experimental parameters on calcium carbonate precipitation. Chemical Engineering Transactions32: 19 -23.
Mastropietro, DJ; Nimroozi, R; Omidian, H (2013).Rheology in pharmaceutical formulations-A perspective.J. Develop. Drugs 2 (2): 1 - 6 .

Nutan, MTN; Reddy, IR(2010). General principles of suspensions. In: Kulshreshtha, A. K. (ed.) Pharmaceutical Suspensions: From Formulation to Development,Springer- Verlag, New York, p.59.

Obunwo, CC; Abia, AA; Iboroma, DS (2014). Studies of sedimentation rates of nontransition alkaline-earth metal carbonates in aqueous medium. IOSR J. Appl. Chem.7 (11): 06 -11 .

Obunwo, CC; Iboroma, DS (2015). Determination of effects of some parameters on the sedimentation rates of strontium and barium carbonates in aqeous medium. IOSR J. of Appl. Chem. 8 (2): 17-21.

Obunwo, CC; Iboroma, SD; Bagshaw, AP (2017). Effects of physical variables on settling velocities of calcium and strontium phosphates in mother solution. J. Appl. Sci. Environ. Manage. 21 (2): 307 - 311.

Patel, MR (2010). Parenteral suspension: An overview. Int'l J. Curr.Pharm. Res. 2 (3):04 - 13.

Punnamaraju, SR (2012). The evaluation of the sedimentation behaviour of magnesiumhydroxide in the never dried state. (unpublished MSc Dissertation). University of Toledo, Toledo, Ohio, USA.

Recillas, S; Rodriguez-Lugo, V; Montero, ML; Viquez-Cano, S; Hernandez, L; Castano, VM (2012). Studies on the precipitation behaviour of calcium phosphate solutions.J.Ceram.Process. Res. 13 (1): 5 - 10.

Victor, NM; Goddy, E; Beauty, A (2007). Studies on the effect of temperature on thesedimentation of insoluble metal carbonates. J. Appl. Sci. Environ. Manage. 11 (4): 67-69.

Zhang, Y; Yin, X; He, Z; Zhang, X; Wen, Y; Wang, $H$ (2015). Modeling the activated sludge thickening process in secondary settlers. Int'l J.Environ. Resources and Public Health 12 (12): 15449 - 15458. 